\title{
Collaborative Research Center TRIP-Matrix-Composite
}

\author{
H. Biermann ${ }^{\mathrm{a} 1}$, Ch.G. Aneziris ${ }^{2}$, M. Kuna ${ }^{3}$ \\ ${ }^{1}$ Institute for Materials Engineering, TU Bergakademie Freiberg, Freiberg, Germany \\ ${ }^{2}$ Institute for Ceramic, Glass and Building Materials Engineering, TU Bergakademie Freiberg, Freiberg, Germany \\ ${ }^{3}$ Institute for Mechanics and Fluid Dynamics, TU Bergakademie Freiberg, Freiberg, Germany
}

\begin{abstract}
A novel composite material is presented, composed of a metastable austenitic stainless steel as matrix which shows the TRIP-effect and MgO-partially stabilized zirconia (PSZ) as reinforcement. Two processing routes will be applied: Cast infiltration of the steel into ceramic performs and powder metallurgy, respectively. In this paper, we will present the principle idea of the collaborative research center.
\end{abstract}

\section{Introduction}

Metal-Matrix-Composites (MMCs) have been examined intensively for decades with the focus mainly being on materials with light metal matrix made of aluminium, magnesium or titanium alloys [1]-[3]. In contrast MMCs with a matrix made of steel have not been examined very much up to now [4], although they exhibit a great potential for high strength and wear resistant composites [5],[6].

In addition an important new aspect exists in the manufacture of adaptive composite materials with which individual phases can react "smart", i.e. adaptively, to the loads. MMCs with such properties were realised through the embedding in of shape memory alloys into an aluminium matrix [7]. This solution made new property combinations possible which do not occur in "traditional" composite materials.

The innovative formulation of the combination of a metallic matrix with a capability for the TRIP-effect (TRIP: Transformation-Induced Plasticity) with a $\mathrm{ZrO}_{2}$-reinforcement which also shows a phase transformation was up until now only described to the authors knowledge by the group of Guo et al. with regard to the mechanical properties for the conventional powder metallurgical route for attaining compact composite materials [8]-[10]. Guo et al. created composite materials made of a TRIP steel matrix with reinforcements made of $\mathrm{ZrO}_{2}$-particles (2Y-PSZ) and examined the dynamic properties in high - deformation rate compression experiments. In this way they could prove that the composite materials show strengths between $1400 \mathrm{MPa}$ and $2100 \mathrm{MPa}$ with up to $12 \%$ strain and that the martensitic transformation occurred in both phases. They examined processing of the steel matrix composite materials without however studying the combinations of the microstructure with regard to the grain sizes of the steel and the $\mathrm{ZrO}_{2}$ powder, the interfaces and the thermodynamic aspects, i.e. the chemical compositions of both phases.

The groups around Chen et al. (e.g.[11]-[13] ) und Jung et al. [14],[15] used the ceramic technology of forming (extruding) and Lopez-Esteban and Bartolomé et al. used slip casting [16] in order to produce components made of $\mathrm{ZrO}_{2}$ and the steel 304 (in accordance with X5CrNi18 10, 1.4301) depending on the sintering (with or without pressure) or functionally graded materials without placing the mechanical properties in the centre of their work. Only in [16] systematic series of composite materials of different ceramic content are described which were also examined with regard to the mechanical and fracture mechanical properties. These publications show the possibilities of the ceramic technologies for the manufacture of composite materials.

a e-mail: biermann@ww.tu-freiberg

This is an Open Access article distributed under the terms of the Creative Commons Attribution-Noncommercial License (http://creativecommons.org/licenses/by-nc/3.0/), which permits unrestricted use, distribution, and reproduction in any noncommercial medium, provided the original work is properly cited. 
Within the framework of this work the concept of a new collaborative research center set up by the German Research Foundation at the Technical University Bergakademie Freiberg with the title "TRIP-Matrix-Composite Design of tough, transformation reinforced composite materials and structures on a $\mathrm{Fe}-\mathrm{ZrO}_{2}$-basis" are to be presented in which the steel-matrix-composite materials are fundamentally examined with two phases capable of transformation (TRIP-steel-matrix and $\mathrm{MgO}$-partially stabilised $\mathrm{ZrO}_{2}$ ). The first results with regard to the properties of a variant of the family of composite materials to be developed were already presented other where [17],[18].

\section{Research programme}

A property matrix is to be set up through the basic understanding and the use of the variation possibilities of the material system consisting of metastable austenitic TRIP-steel and $\mathrm{MgO}$ partially stabilised $\mathrm{ZrO}_{2}$, which opens up use in completely different fields of application with small deviations from the basic system.

With this concept the manufacture of components which are partially reinforced and near net shape, particle reinforced composite materials and filigrain honeycombs are in principle possible.

The TRIP-MATRIX-COMPOSITES are to be created on the basis of the materials developed at the TU Bergakademie Freiberg. With the austenitic steel casting with TRIP-effect [19],[20],[21] and also the ceramic [22] it concerns patented or patent registered materials, the principle of the TRIP-Matrix-Composite Materials was also registered [23]. The innovation with the metallic matrix is based on the fact that the steel as a casting material has unusually high fracture strains up to $70 \%$ with very high strengths of over $700 \mathrm{MPa}$ due to the TRIP effect see [20],[21]. These properties can be set through targeted alloy design.

For the material manufacture two fundamentally different paths are to be pursued:

- On the one hand a penetration structure is to be inserted with which the ceramic components as foam or porous ceramic body as infiltrated with the cast steel material. In this way either an active infiltration supported by suitable (e.g. coated) interfaces or a forced infiltration under metallostatic pressure or in the low pressure process is used. Fig. 1a and b show a symbolic representation of these two variants.

- On the other hand a powder metallurgical path via the forming (at room temperature) is being pursued and composite material studied in with which $\mathrm{ZrO}_{2}$-particles are incorporated in a matrix made of TRIP steel. With this powder metallurgical route a new and innovative scientific path for manufacture of metal matrix compounds is being suggested which permits all forming possibilities of the ceramic shaping technologies. The preform can either be compacted before or after sintering (compact particle TRIP matrix composite material fig. 1c) through a suitable process route or used as a macro or microporous "honeycomb" (fig. 1d). As an additional characteristic it should be mentioned that the material presented via the powder metallurgical route can have a fraction between 0 and $70 \%$ whereby a large spread of the microstructures and the inner interfaces can also be set via the size of the powder particle sizes.

Fig. 1 thus shows the four composite material variants in chart form which are based on both base systems $\mathrm{MgO}$ partially stabilised $\mathrm{ZrO}_{2}$-ceramics and austenitic TRIP-steel.

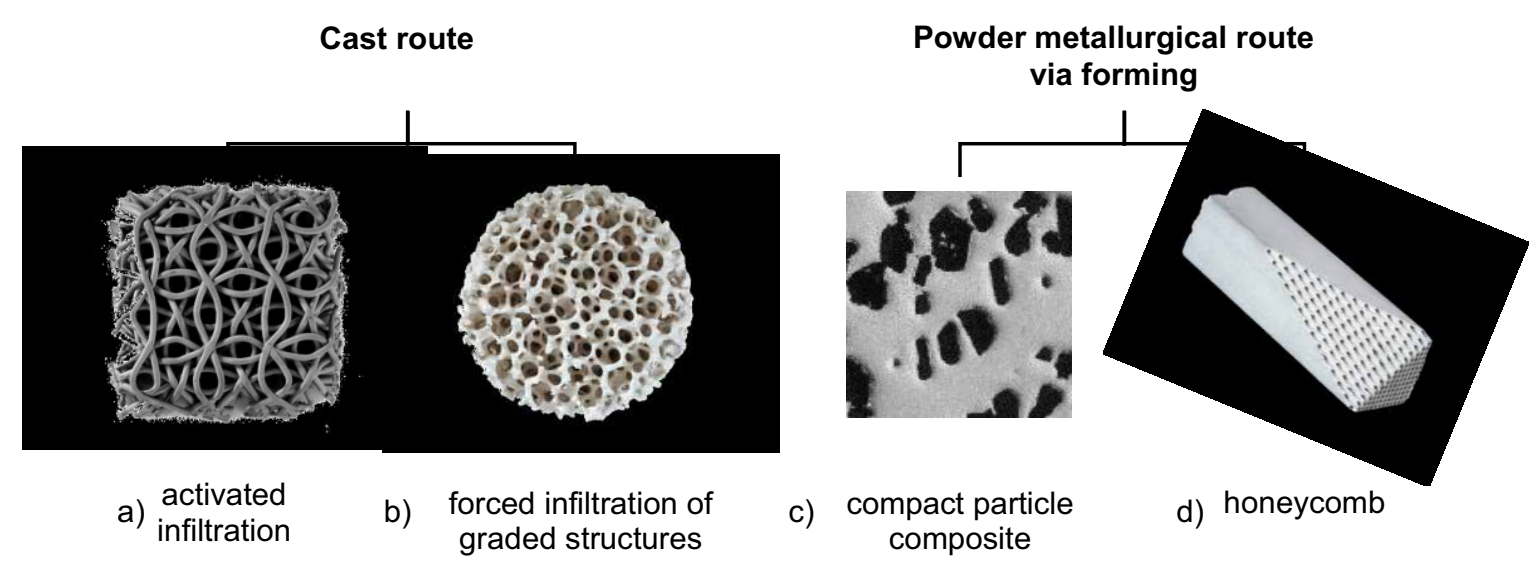

Fig 1: Process for manufacture of the new material classification made of $\mathrm{MgO}$-part stabilised $\mathrm{ZrO}_{2}$ and cast steel with TRIP-effect which is in the focus of the collaborative research center. 
The application of bionic principles on the TRIP-MATRIX-COMPOSITES is ultimately to lead via the steel infiltration of ceramic macrostructures to components which are partially reinforced in the maximum loaded areas and with which a maximum bearing strength is attained in the sense of lightweight construction with minimum use of materials. Fig. 1a can give an initial impression. The "spaghetti" ceramic presented and the possible hollow variant (macaroni structure) can be formed from a viscous mixture through the forming (extrusion) and the subsequent further processing for any structures [18]. In particular it is possible to use the compressive strength of the ceramics in structures for load bearing and load distribution in a targeted way. This manufacturing technology also allows the manufacture of graded ceramic macrostructures.

The ceramic_preforms are to be infiltrated with the cast steel material in green state or following sintering in a low pressure process. When infiltrating the green ceramics the sintering process can occur with molten steel during the infiltration which allows an extreme energy saving manufacturing process to be realised.

\section{Central issues of the collaborative research center}

The possibilities for set up of the desired properties of the TRIP-MATRIX-COMPOSITES are based on the self reinforcing effect of the ceramic components (through mechanical, thermal and/or chemically induced transformation), the transformation behaviour of the steel (targeted setting up of the TRIP effect with reference to yield point, uniform elongation, strength and strain hardening and the martensit start temperature (Ms) as well as the Md temperature where the martensite is formed in an deformation-induced way) and the metal-ceramic interface (size, strength, coating). New properties of the TRIP-Matrix- $\mathrm{ZrO}_{2}$-composite materials are to be expected through the combined reinforcement of both martensitic transformations: The transformation of the $\mathrm{ZrO}_{2}$-ceramics from the tetragonal to the monoclinic phase leads to local residual compressive stresses at points of high stress concentration and these are particularly well borne by ceramic materials and increase the fracture toughness of the composite.

On the other hand the TRIP-steel contributes to additional deformability and increased strength at highly loaded points due to its ability in deformation-induced martensitic transformation (TRIP-effect). The steel also guarantees good basic toughness in the composite material. In the case of e.g. an dynamic impact overload the ceramic phase will transform whereby mircocracks in the ceramics could emerge. These microcracks are however caught in the steel matrix with its excellent deformability and outstanding strain hardening. The suggested composite materials should thus - according to our working hypothesis - be able to resist deforming and stress controlled overloads well and show particularly damage tolerant behaviour.

The linking of the modern steel cast process with the targeted local reinforcement means that cost effective new components can be created which integrate several functions in a component. Through this approach the new TRIP-MATRIX-COMPOSITE can be used to accept loads over the smallest area whereby the sparing use of material guarantees a high degree of efficiency and economy of the new process. It would thus be possible to create extremely high local hardness in a component whereas other areas (e.g. for bolts) would show the necessary ductility. Of course it is possible to transfer high compressive forces with high damage tolerance at the same time through the targeted incorporation of directional ceramic reinforcements. An optimisation of the reinforcement properties is also possible through a local variation of the material design. In addition refined components with a gradual transition of the volume fraction of the ceramic phase from the surface to the core are to be manufactured with this process in order to thus attain a variable, location dependent functionality. This is meant to include components which show extreme resistance to wear at the surface due to a high ceramic fraction and show an extremely tough core with adequate strength due to a low ceramic fraction on the inside for example.

The shaping and design possibilities of the TRIP-MATRIX-COMPOSITES in relation to the various components and semi-finished products are presented for all materials and material variants in fig. 2. 


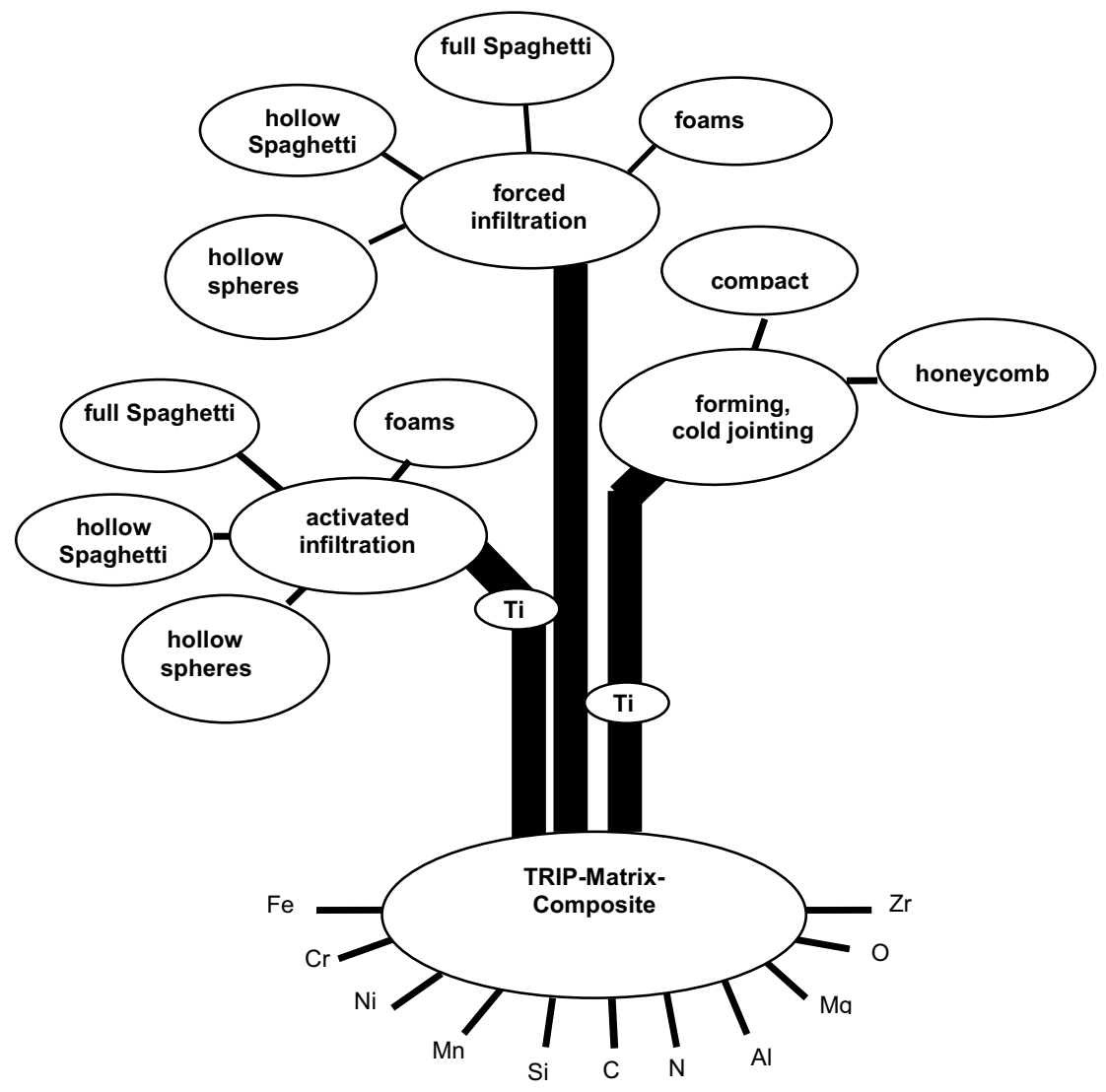

Fig 2: Tree of the new composite materials made of TRIP cast steel and $\mathrm{MgO}$ partially stabilised $\mathrm{ZrO}_{2}$-with or without $\mathrm{MgAl}_{2} \mathrm{O}_{4}$ spinel which are to be developed within the research center framework with indication of the chemical elements of the matrix and the ceramics involved. Ti is potentially added as powder or coating where appropriate.

The composition of the ceramic base materials is of particular significance. Through the mixing of the base materials the phase fractions of the cubic, tetragonal and monoclinical phases can be set in a targeted way via the spinel addition or the in situ spinel formation. We see a further advantage in the fact that the selected system of the $\mathrm{MgO}-$ $\mathrm{ZrO}_{2}$-ceramics shows a significant difference to the other stabilisations of zirconia with $\mathrm{CeO}_{2}$ or with the frequently used $\mathrm{Y}_{2} \mathrm{O}_{3}$ : On infiltration or sintering, spinel is formed in situ through a chemical reaction between the $\mathrm{MgO}^{-\mathrm{ZrO}} \mathrm{Z}_{2}$ and the alloying elements from the steel matrix. These spinels can help to bring about a targeted chemical bonding between ceramic and steel which makes a contribution to the design of the interfaces. As an alternative the effect of interface active elements (as an additional material in powder form or as a coating) such as Ti is to be investigated which is known for an improvement of the wettability of $\mathrm{ZrO}_{2}$ with molten steel.

Within the framework of the scientific-technological research of the collaborative research center the following innovations of scientists of the TU Bergakademie Freiberg are applied:

- $\quad$ The TRIP cast steel material [19],[20],[21]

- the $\mathrm{MgO}$ partially stabilised $\mathrm{ZrO}_{2}$-material [22]

- the combination of both innovative materials to composite materials [17],[23]

- a targeted interface design

- the application of the plastic forming to viscous (green) materials which are kneadable at room temperature for the manufacture of composite materials [17],[18]

- $\quad$ honeycombs via the forming

- "cold jointing" of kneadable steel powder- $\mathrm{ZrO}_{2}$-powder masses

- the adaptation of the bionic principle on the composite materials through the freedom of the new technology

- the created ceramic structures (full and hollow "spaghetti" bodies) and the honeycomb

- the creation of partially reinforced components which are near net-shape through infiltration. 
The most up to date methods of structural analysis and material and component testing are used to reach the goals. This includes a detailed investigation of the real structure and the structure property relations of the materials and prototypes with the in-situ loading in the scanning electron microscope, in the computer tomography and in X-Ray and neutron diffractometers and the mechanical and fracture mechanical properties under static, dynamic, cyclical and multi axis load. Quantum mechanical calculations also make an essential contribution for the application-specific optimisation of the structure and material design (while using the density functional theory), the streaming and solidification simulation of the metal infiltration, the thermodynamic modelling of the materials and interfaces and also the continuum and damage mechanical modelling of the mechanical properties

We see possible uses for the various TRIP-Matrix-Composites in components exposed to high wear such as e.g. in preparation machines, in drilling engineering or tunnel construction where good opportunities to increase strength are seen through the partial reinforcement of complex multifunctional components. In addition particular attention is paid to crash elements which are relevant in the field of the motor vehicle industry (car, truck, train engineering) and aviation (helicopter, light aircraft). In this the high specific energy absorption of the honeycomb structures is of particular importance (see [17],[18]). In addition further high strength or strongly reinforcing material variants are to be developed, the potential fields of use for which are only identified in the course of the undertaking.

\section{Acknowledgement}

The authors wish to express their thanks for the support of the German Research Foundation for the collaborative research center "TRIP-MATRIX-COMPOSITE" (SFB 799).

\section{References}

[1] S. Suresh, A. Mortensen, A. Needleman, A. (eds.): Fundamentals of Metal Matrix Composites, ButterworthHeinemann, Boston, 1993

[2] N. Chawla, K.K. Chawla, K.K.: Metal Matrix Composites, Springer-Verlag, New York, 2006

[3] K.U. Kainer, (ed.), Metal Matrix Composites, Custom-made Materials for Automotive and Aerospace Engineering, Wiley-VCH, Weinheim, 2006

[4] A. Mortensen, T.W. Clyne, in M. Rühle (ed.): European White Book. Max-Planck-Institut für Metallforschung, Stuttgart, 2001, p. 210

[5] M. Karlsohn, S. Weber, S. R. Alavi Zaree, S. Müller, W. Theisen, W. Reimers, A. R. Pyzalla, Powder Metallurgy 2008, 51, 31-37.

[6] D. Wittig, A. Glauche, C.G. Aneziris, T. Minghetti, C. Schelle, T. Graule, J. Kuebler, Mater. Sci. Eng. A 2008, 488, 580-585

[7] V. Michaud, Scripta Mater. 2004, 50, 249-253

[8] Y. Guo, Y. Zhou, D. Li, X. Duan, T. Lei, J. Mat. Sci. Technol. 2003, 19, 137-140

[9] Y. Guo, Y. Zhou, X. Duan, D. Li., T. Lei, Ceramics Int. 2004, 30, 75-80

[10] Y. Zhou, Y. Guo, D. Li, X. Duan, Trans. Nonferrous Met. Soc. China, 2003, 3, 1086-1091

[11] Z. Chen, K. Ikeda, T. Murakami, T. Takeda, J. Am. Cer. Soc. 2000, 83, 1081-1086

[12] Z. Chen, K. Ikeda, T. Murakami, T. Takeda, J. Mater. Processing Techn. 2001, 114, 154-160

[13] Z. Chen, K. Ikeda, T. Murakami, T. Takeda, J.-X. Xie, J. Mater. Processing Techn. 2003, 137, 10-16

[14] Y.G. Jung, S.C. Choi, C.-S. Oh, J. Mater. Sci. 1997, 32, 3841-3850

[15] Y.G. Jung, U. Paik, S.C. Choi, J. Mater. Sci. 1999, 34, 5407-5416

[16] S. Lopez-Esteban, J.F. Bartolomé, C. Pecharroman, J.S. Moya, J. Europ. Cer. Soc. 2002, 22, 2799-2804

[17] C.G. Aneziris, W. Schärfl, H. Biermann, U. Martin, Int. J. Appl. Ceram. Technol., 2008, DOI:10.1111/j17447402.2008.02321.x

[18] C.G. Aneziris, H. Biermann, W. Schärfl, U. Ballaschk, U. Martin. In: Verbundwerkstoffe, Hrsg. W. Krenkel, Wiley-VCH, Weinheim,2009, S. 147-154

[19] A. Weiß, P.R. Scheller, H. Gutte, German Patent Registration AZ 102006033973

[20] A. Jahn, A. Kovalev, A. Weiß, P.R. Scheller, S. Wolf, L. Krüger, S. Martin, U. Martin, D. Rafaja: Proc. ESOMAT 2009, Prague, September 2009.

[21] A. Weiß, H. Gutte, A. Jahn, P. R. Scheller, Materialwissenschaft und Werkstofftechnik 2009: DOI:10.1002/mawe.200800361

[22] C.G. Aneziris, H.R. Maier, E.M. Pfaff, German Patent DE 199 38 752, awarded 05.12.2002

[23] C.G. Aneziris, P.R. Scheller, H. Biermann, Patent Registration PCT/DE2007/002287 